\title{
Differential clinical benefits of continuous blood purification treatment in critically ill patients with variable APACHE II scores
}

\author{
RUI-XIANG ZHOU* ${ }^{*}$ WEI DAI ${ }^{*}$ and CHAO-LIANG HU \\ Intensive Care Unit of The First Hospital of Wuhan, Wuhan, Hubei 430022, P.R. China
}

Received March 5, 2018; Accepted September 27, 2018

DOI: $10.3892 / \mathrm{etm} .2019 .7617$

\begin{abstract}
The present study aimed to assess whether the Acute Physiology And Chronic Health Evaluation (APACHE) II score may be used to predict whether critically ill patients benefit from continuous blood purification (CBP) treatment. A total of 115 critically ill patients were retrospectively reviewed and grouped according to their baseline APACHE II scores. Each group was further divided into 2 groups based on whether they received CBP or not. At $72 \mathrm{~h}$ after CBP treatment, clinical indicators comprising the plasma levels of inflammatory cytokines, including tumor necrosis factor (TNF)- $\alpha$, interleukin (IL)-6 and IL-8, as well as endotoxin and procalcitonin (PCT), and severity scores (APACHE II, multiple organ dysfunction syndrome and systemic inflammatory response syndrome), were analyzed in all patients. It was observed that while CBP slightly reduced the severity scores in all patients, it significantly improved those in patients with an APACHE II score of 20-29 $(\mathrm{P}<0.05)$. Similarly, the plasma levels of TNF- $\alpha$, IL-6, IL-8, endotoxin and PCT were significantly lower in patients receiving $\mathrm{CBP}$ than in those without $\mathrm{CBP}$ when the APACHE II score was 20-29 $(\mathrm{P}<0.05)$. Furthermore, CBP treatment significantly decreased the fatality rate and length of stay at the intensive care unit (ICU) for critically ill patients with an APACHE II score of 20-29 (P<0.05). In conclusion, CBP significantly decreases the inflammatory response, shortens the length of stay at the ICU and improves the prognosis for critically ill patients with an APACHE II score of 20-29 points. This observation suggests that the APACHE II score is an important clinical indicator to determine the potential benefit of CBP therapy in critically ill patients.
\end{abstract}

Correspondence to: Professor Chao-Liang $\mathrm{Hu}$, Intensive Care Unit of The First Hospital of Wuhan, 215 Zhongshan Road, Wuhan, Hubei 430022, P.R. China

E-mail: chaoliang212@sina.com

*Contributed equally

Key words: inflammatory, cytokine, continuous blood purification, acute physiology and chronic health evaluation II, retrospective study, interleukin-6, interleukin-8, endotoxin

\section{Introduction}

Multiple organ dysfunction syndrome (MODS), a final stage of numerous fatal infections and non-infectious diseases, is the leading cause of death in critically ill patients (1). It is widely thought that an uncontrolled inflammatory response is the pathophysiological basis of MODS. Inflammatory mediators, including interleukin (IL)-6, IL-8 and tumor necrosis factor (TNF)- $\alpha$, cause tissue damage, blood hypercoagulability and microcirculation disturbances, thereby leading to MODS and multiple organ failure (2-5). Therefore, eliminating or reducing the level of inflammatory factors is the key in the prevention and treatment of MODS.

For $>70$ years, renal replacement therapy has been used to treat patients with acute renal injury. Recently, continuous blood purification (CBP) for the treatment of patients with non-renal diseases has drawn increasing attention, and has been widely used in various clinical departments, including critical care medicine units (6). The aim of CBP in the treatment of non-renal diseases is to maintain the blood volume (e.g., in cases of heart failure), eliminate toxins, restore the electrolyte balance, control the body temperature and eliminate inflammatory mediators (7). Critical illness, usually accompanied by MODS, is characterized by diverse causes, rapid progression and a complicated pathophysiology (8). At times, it is difficult for clinicians to perform the CBP procedure for these patients. It has been indicated that, while it improves the prognosis of patients, early CBP treatment may cause complications, including hypotension, coagulation dysfunction, nutrition and therapeutic drug loss and catheter-associated infections (9). At present, there is no standard regarding the suitable timing for CBP treatment (10), which needs to be determined for critically ill patients.

There is a positive correlation between Acute Physiology And Chronic Health Evaluation (APACHE) II, a scoring system used to evaluate the severity of a patient's illness, and the risk of mortality $(11,12)$. Other scoring systems, including MODS and systemic inflammatory response syndrome (SIRS), are also used to evaluate the severity of a patient's illness (13-16). In the present study, the clinical data of critically ill patients who had been admitted to the intensive care unit (ICU) were retrospectively reviewed and the value of the APACHE II score in guiding early CBP treatment was investigated. 


\section{Materials and methods}

Patients. The present study included a total of 115 critically ill patients admitted to the ICU of the First Hospital of Wuhan (Wuhan, China) from January 2013 to December 2016. The inclusion criteria were as follows: i) An APACHE II score of $>15$ points; and ii) no history of any obvious organ dysfunction. Exclusion criteria included i) allergic reaction to the filter or the refusal of blood transfusion and ii) the time from ICU admission to death was $<24 \mathrm{~h}$. All patients were provided with the appropriate treatment according to the primary disease, e.g., anti-infection, organ function support, liquid management or nutritional support. The current study was approved by the Ethics Committee of the First Hospital of Wuhan (Wuhan, China). Written informed consent was obtained from all patients or their parents or next of kin.

Experimental design. The patients enrolled were divided into 3 groups based on their APACHE II score on the first day at the ICU. The patients in group A had an APACHE II score of 15-19, while those in group B had a score of 20-29 points and those in group $\mathrm{C}$ had a score of $\geq 30$ points. These APACHE II scores were arbitrarily selected to group the patients based on an analysis of the clinical data from critically patients over the last five years. Each group was then further divided into 2 subgroups depending on whether the patients received CBP treatment or not. Patients in groups $\mathrm{A} 1, \mathrm{~B} 1$ and $\mathrm{C} 1$ received $\mathrm{CBP}$ treatment, while patients in groups $\mathrm{A} 2$, B2 and $\mathrm{C} 2$ did not.

CBP treatment. A single needle double lumen catheter was inserted into the femoral vein or internal jugular vein for the establishment of an extracorporeal circulation. All patients in the first group (group 1) underwent pre-dilution continuous veno-venous hemofiltration $(\mathrm{CVVH})$ and received blood purification. CVVH was performed using the Fresenius multiFitrate system and Ultraflux AV600S hemofilters (Fresenius Medical Care, Bad Homburg v.d.H., Germany). The blood flow rate was $150-200 \mathrm{ml} / \mathrm{min}$ and the displacement fluid velocity was $2,000-3,500 \mathrm{ml} / \mathrm{h}$. CVVH was performed at a dose of $30 \mathrm{ml} / \mathrm{kg} / \mathrm{h}$. The volume load of the patients was dynamically assessed to adjust the liquid balance and the results of the blood gas analysis and biochemical examination were monitored. For anti-coagulation, patients with no elevated risk of bleeding were treated with heparin with a loading dose of $10-50 \mathrm{U} / \mathrm{kg}$ and a loading speed of 2.5-20 U/min to maintain the activated partial thromboplastin time at 30-60 sec. Patients with an elevated risk of bleeding or with bleeding were treated with non-heparin anti-coagulants.

Cytokine measurement. Plasma levels of inflammatory proteins [endotoxin and procalcitonin (PCT)] in patients were measured prior to or $72 \mathrm{~h}$ after CBP treatment using an automatic biochemical analyzer (HF-240; Jinan Chinese Medical Instrument Ltd., Jinan, China). Plasma levels of cytokines were detected using TNF- $\alpha$ (cat. no. EK0525), IL-6 (cat. no. EK0410) and IL-8 (cat. no. EK0413) ELISA kits supplied by Wuhan Boster Biological Technology, Ltd. (Wuhan, China).
Severity scoring. Severity scoring was performed every $24 \mathrm{~h}$ using APACHE II, MODS and SIRS ICU scoring systems $(14,17,18)$. The APACHE II score for each patient was determined on the first day at the ICU. The incidence of MODS and mortality were recorded two weeks after admission to the ICU. The length of stay at the ICU was also recorded.

Statistical analysis. Statistical analysis was performed using SPSS 18 statistical software (SPSS, Inc., Chicago, IL, USA). Values are expressed as the mean \pm standard deviation. Student's t-test was used to determine differences between the two groups. $\mathrm{P}<0.05$ was considered to indicate a statistically significant difference.

\section{Results}

Patient characteristics. A total of 115 patients with critical illness, of which 60 were male and 55 were female, were enrolled in the present study. The characteristics of the patients are listed in Table I. There was no significant difference in gender, age, primary disease, course of disease, basic renal function and cardiac function between groups $\mathrm{A} 1$ and $\mathrm{A} 2$, $\mathrm{B} 1$ and $\mathrm{B} 2$, or $\mathrm{C} 1$ and $\mathrm{C} 2(\mathrm{P}>0.05)$. Of note, treatments given to patients based on the primary disease were not different between groups (A1-C1 vs. A2-C2). Steroids were not used in the patients of this cohort.

Effect of CBP treatment on the severity scores of critically ill patients. To determine whether the APACHE II score prior to treatment was associated with the outcome, the APACHE II, MODS and SIRS severity scores of the critically ill patients were recorded at $72 \mathrm{~h}$ after treatment. As presented in Fig. 1, as expected, the APACHE II, MODS and SIRS scores were decreased at $72 \mathrm{~h}$ after treatment with CBP compared with those without treatment, which suggests a clinical improvement after treatment with CBP in all groups. It was observed that patients with lower APACHE II, MODS or SIRS scores demonstrated a greater improvement than those with higher scores, i.e., the scores in patient group A exhibited a larger decrease after treatment compared with those in group C.

It was then assessed which group of patients benefited the most from CBP. As presented in Fig. 1, CBP treatment did not provide a significant benefit for patients with an APACHE II score of 15-19 (Group A) or $>30$ points (Group C): The improvement in the APACHE II, MODS or SIRS score for patients receiving CBP treatment (Group A1 or $\mathrm{C} 1$ ) was not significantly different from that of patients who did not (Group A2 or C2). However, for patients with an APACHE II score between 20 and 29 (Group B), CBP treatment significantly decreased the APACHE II, MODS and SIRS scores when compared with those of patients who did not $(\mathrm{P}<0.05$, B1 vs. B2). Taken together, these results suggest that $\mathrm{CBP}$ treatment has a differential effect on patients with different APACHE II scores.

Effect of CBP treatment on the plasma levels of inflammatory proteins in critically ill patients. Next, it was assessed whether CBP treatment affected the levels of inflammatory proteins and cytokines in patients with different APACHE II scores treated with or without CBP. As presented in Fig. 2, it appeared that treatment for $72 \mathrm{~h}$ slightly decreased the levels 
Table I. Patient characteristics.

\begin{tabular}{|c|c|c|c|c|c|c|c|c|c|c|c|}
\hline \multirow[b]{2}{*}{ Group } & \multirow[b]{2}{*}{$\mathrm{n}$} & \multirow[b]{2}{*}{$\begin{array}{l}\text { Gender } \\
(\mathrm{M} / \mathrm{F})\end{array}$} & \multirow[b]{2}{*}{$\begin{array}{c}\text { Age } \\
\text { (years) }\end{array}$} & \multicolumn{4}{|c|}{ Primary disease } & \multirow[b]{2}{*}{$\begin{array}{c}\text { Disease course } \\
\text { (days) }\end{array}$} & \multirow[b]{2}{*}{$\begin{array}{c}\mathrm{Cr} \\
(\mu \mathrm{mol} / 1)\end{array}$} & \multirow[b]{2}{*}{$\begin{array}{c}\text { BUN } \\
(\mathrm{mmol} / \mathrm{l})\end{array}$} & \multirow[b]{2}{*}{$\begin{array}{c}\text { NT-proBNP } \\
\text { (ng/l) }\end{array}$} \\
\hline & & & & $\begin{array}{l}\text { SAP } \\
\mathrm{n}(\%)\end{array}$ & $\begin{array}{l}\text { Sepsis } \\
\mathrm{n}(\%)\end{array}$ & $\begin{array}{l}\text { ARDS } \\
\mathrm{n}(\%)\end{array}$ & $\begin{array}{l}\text { Other } \\
\mathrm{n}(\%)\end{array}$ & & & & \\
\hline A1 & 19 & 1( & $56 \pm 14$ & $4(21.1)$ & $9(47.3)$ & $4(21.1)$ & $2(10$ & $2.4 \pm 1.3$ & 21.4 & $14.7 \pm 4.4$ & 14,1 \\
\hline $\mathrm{A} 2$ & 19 & $10 / 9$ & $54 \pm 15$ & $4(21.1)$ & $10(52.6)$ & $4(21.1)$ & $1(5.3)$ & $2.5 \pm 1.4$ & $154.5 \pm 22.1$ & $14.9 \pm 4.5$ & $14,251 \pm 399.3$ \\
\hline B1 & 19 & $9 / 10$ & $57 \pm 13$ & $4(21.1)$ & $9(47.3)$ & $5(26.3)$ & $1(5.3)$ & $2.6 \pm 1.2$ & $150.6 \pm 25.2$ & $14.4 \pm 4.9$ & $14,521 \pm 432.6$ \\
\hline $\mathrm{B} 2$ & 20 & $10 / 10$ & $55 \pm 13$ & $5(26.3)$ & $10(52.6)$ & $4(21.1)$ & $1(5.3)$ & $2.5 \pm 1.3$ & $149.3 \pm 24.8$ & $14.8 \pm 5.2$ & $14,462 \pm 396.5$ \\
\hline $\mathrm{C} 1$ & 19 & $10 / 9$ & $56 \pm 14$ & $4(21.1)$ & $9(47.3)$ & $4(21.1)$ & $2(10.5)$ & $2.6 \pm 1.4$ & $156.9 \pm 24.9$ & $15.1 \pm 4.3$ & $14,568 \pm 387.8$ \\
\hline $\mathrm{C} 2$ & 19 & $9 / 10$ & $56 \pm 13$ & $4(21.1)$ & $8(42.1)$ & $5(26.3)$ & $2(10.5)$ & $2.6 \pm 1.3$ & $156.1 \pm 25.1$ & $15.2 \pm 5.2$ & $14,606 \pm 406.4$ \\
\hline
\end{tabular}

Groups: A, APACHE II score 15-19; B, APACHE II score 20-29; C, APACHE II score 230; 1, CBP treatment; 2, no CBP treatment. CBP, continuous blood purification; APACHE, Acute Physiology And Chronic Health Evaluation; M, male; F, female; SAP, severe acute pancreatitis; ARDS, acute respiratory distress syndrome; Cr, creatinine (71-133 mmol/l); BUN, blood urea nitrogen (2.5-7.1 mmol/l); NT-proBNP, $\mathrm{N}$-terminal pro b-type natriuretic peptide (NT-proBNP $<300 \mathrm{ng} / \mathrm{l}$ indicates a low risk of heart failure; NT-proBNP $<450 \mathrm{ng} / \mathrm{l}$ for patients $\leq 50$ years, $<900 \mathrm{ng} / \mathrm{l}$ for patients $50-75$ years and $<1,800 \mathrm{ng} / \mathrm{l}$ for patients $\geq 75$ years).

A

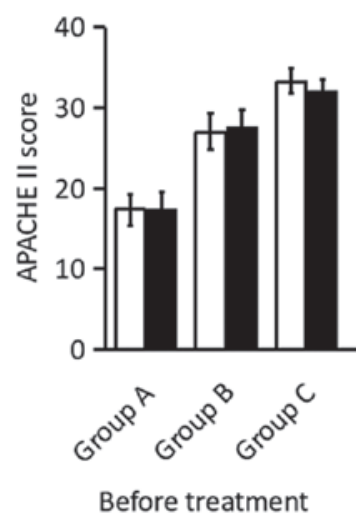

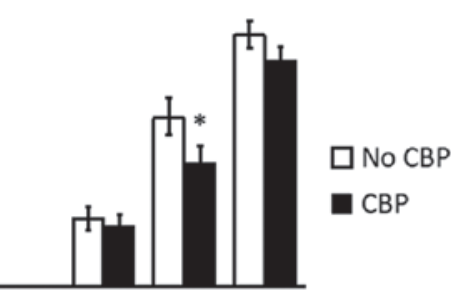

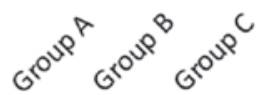

After treatment

C

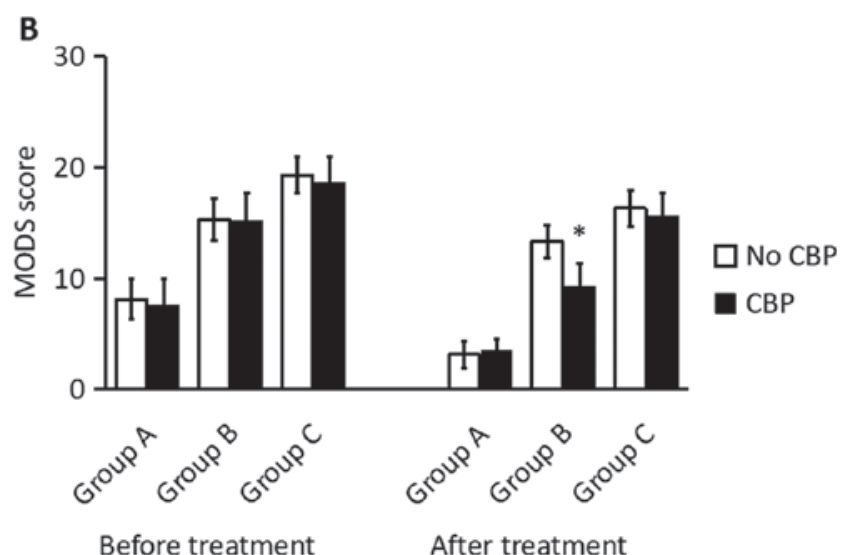

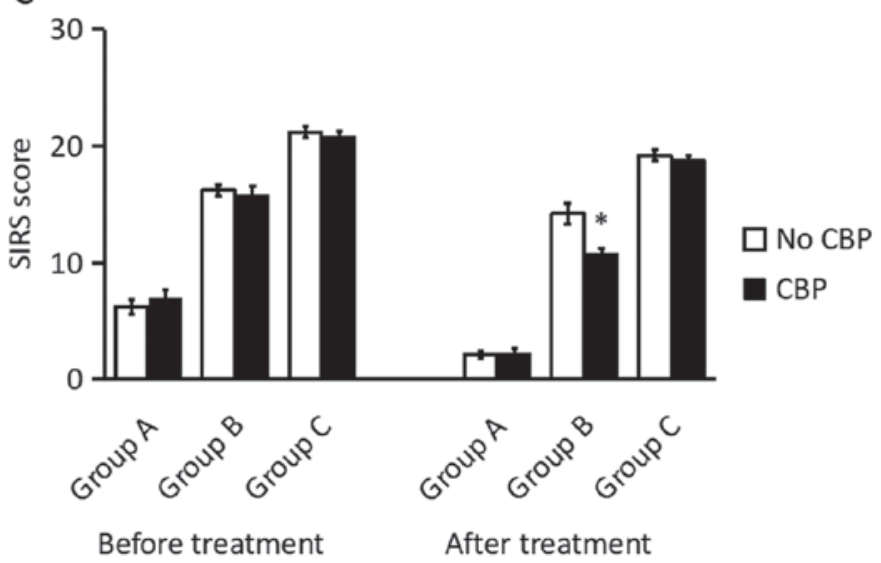

Figure 1. Effect of CBP treatment on severity scores in critically ill patients. Graphs showing scores of (A). APACHE II, (B) MODS and (C) SIRS in critically ill patients receiving treatment with or without CBP. Groups: A, APACHE II score of 15-19 points; B, APACHE II score of 20-29 points; C, APACHE II score of $\geq 30$ points. ${ }^{\mathrm{P}}<0.05$ vs. no CBP treatment. MODS, multiple organ dysfunction syndrome; SIRS, systemic inflammatory response syndrome; CBP, continuous blood purification; APACHE, Acute Physiology And Chronic Health Evaluation.

of endotoxin and PCT in each group. The results indicated that in groups $\mathrm{A}$ and $\mathrm{C}$, there was no significant difference in the endotoxin levels between patients treated with or without CBP. By contrast, for patients in group B, CBP treatment significantly decreased the endotoxin levels $(\mathrm{P}<0.05, \mathrm{~B} 1$ vs. B2; Fig. 2A). Regarding the levels of PCT, while CBP did not achieve any significant improvement in patient group A $(\mathrm{P}>0.05, \mathrm{~A} 1$ vs. A2), the level of PCT in groups B and $\mathrm{C}$ was 
A

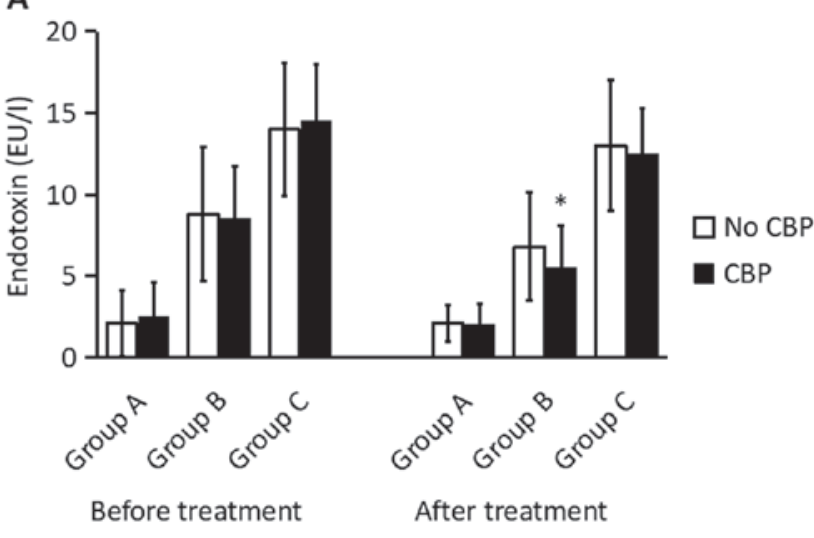

B

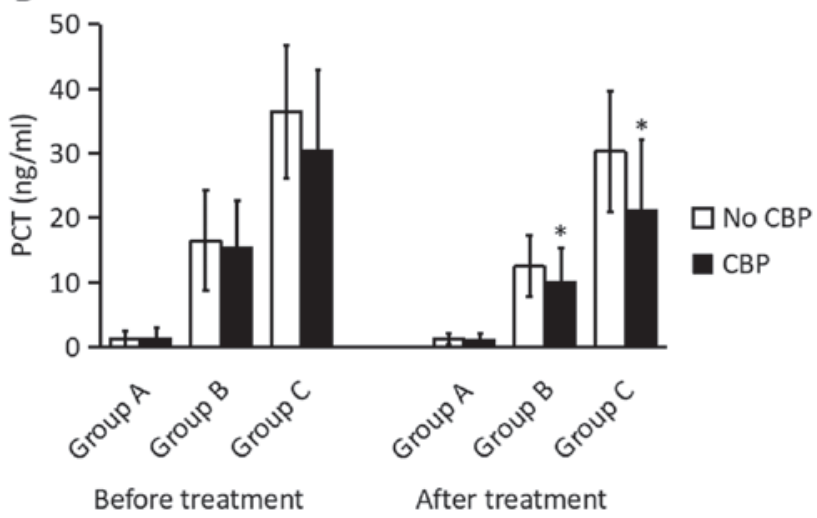

Figure 2. Effect of CBP treatment on plasma levels of endotoxin and PCT in critically ill patients. Graphs showing plasma levels of (A) endotoxin and (B) PCT in critically ill patients receiving treatment with or without $\mathrm{CBP}$. Groups: A, APACHE II score of 15-19 points; B, APACHE II score of 20-29 points; C, APACHE II score of $\geq 30$ points. " $\mathrm{P}<0.05$ vs. no CBP treatment. CBP, continuous blood purification; PCT, procalcitonin; APACHE, Acute Physiology And Chronic Health Evaluation.

significantly lower in patients who received CBP treatment ( $\mathrm{P}<0.05$, B1 vs. $\mathrm{B} 2$ or $\mathrm{C} 1$ vs. $\mathrm{C} 2$; Fig. $2 \mathrm{~B})$.

Regarding the inflammatory cytokine levels, CBP treatment did not significantly improve the levels of TNF- $\alpha$, IL- 6 or IL-8 in patient group A, while CBP treatment significantly decreased the levels of IL-6 and IL-8 in patient group B and $\mathrm{C}(\mathrm{P}<0.05$, $\mathrm{B} 1$ vs. $\mathrm{B} 2$ or $\mathrm{C} 1$ vs. $\mathrm{C} 2$; Fig. 3). Taken together, these results suggest that $\mathrm{CBP}$ treatment preferentially impacts patients with APACHE II scores of 20-29 and $>30$.

Effect of CBP treatment on clinical indicators in critically ill patients. Given the improved severity scores and reduced levels of pro-inflammatory proteins and cytokines by CBP treatment in patient group $\mathrm{B}$, the present study then aimed to determine whether CBP treatment improves other clinical indicators. For this, the occurrence of MODS, the mortality rate and the length of stay at the ICU in these three patient groups was determined. As presented in Table II, after 2 weeks of treatment, the mortality rate and the occurrence of MODS were was significantly lower in patient groups $\mathrm{B}$ and $\mathrm{C}$ who received CBP treatment than in those who received no CBP treatment $(\mathrm{P}<0.05)$. In addition, the length of stay at the ICU was shorter for patient groups $\mathrm{B}$ and $\mathrm{C}$ who received $\mathrm{CBP}$ treatment than those without $\mathrm{CBP}$ treatment $(\mathrm{P}<0.05$; Table II).
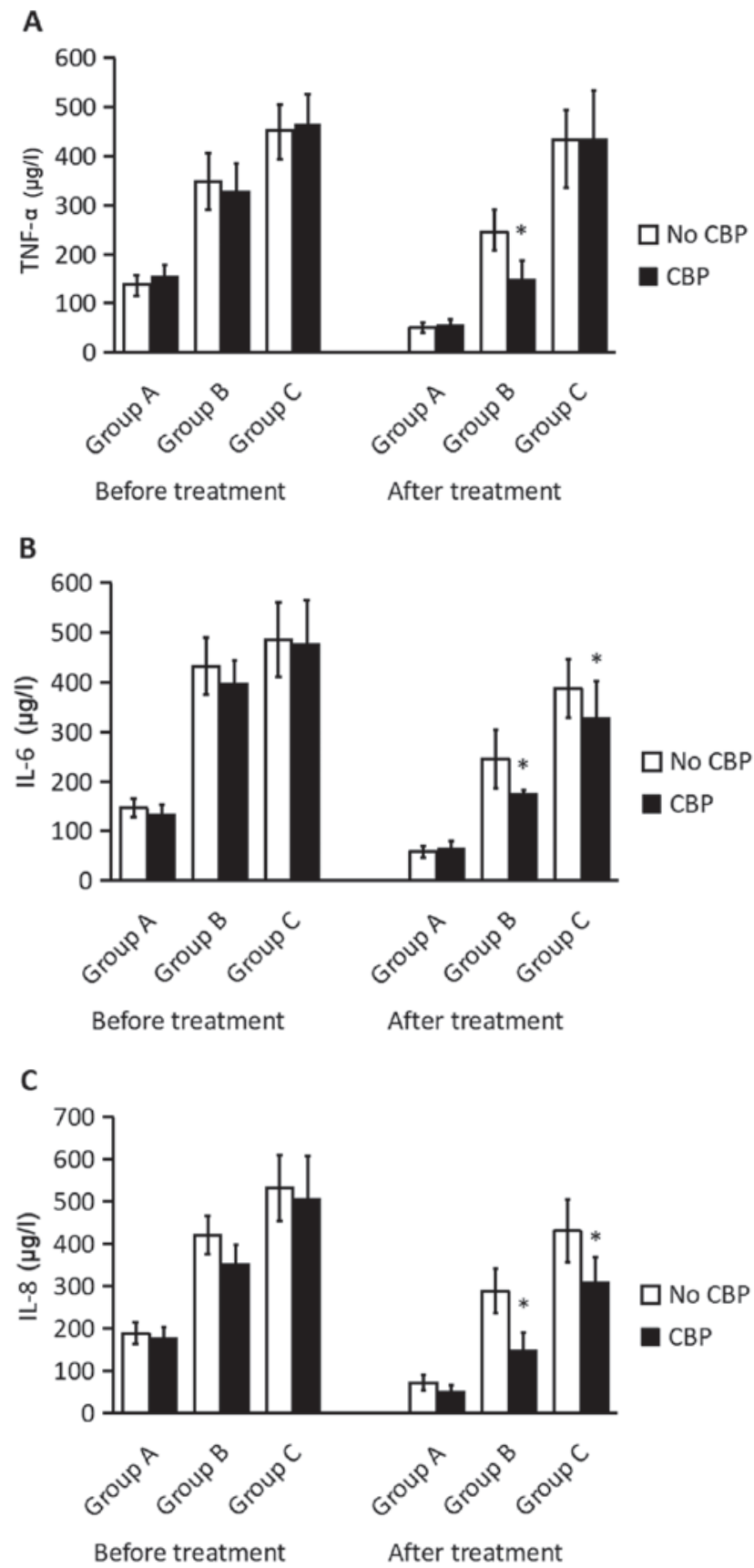

Figure 3. Effect of CBP treatment on plasma levels of cytokines in critically ill patients. Graphs presenting the plasma levels of (A) TNF- $\alpha$, (B) IL-6 and (C) IL-8 in critically ill patients receiving treatment with or without CBP. Groups: A, APACHE II score of 15-19 points; B, APACHE II score of 20-29 points; C, APACHE II score of $\geq 30$ points. "P<0.05 vs. no CBP treatment. $\mathrm{CBP}$, continuous blood purification; TNF, tumor necrosis factor; IL, interleukin; APACHE, Acute Physiology And Chronic Health Evaluation.

Furthermore, the percentage of cases with MODS was slightly but not significantly reduced in group B1 vs. B2. In the patients of groups A and C, CBP treatment did not significantly affect the percentage of cases of MODS, the mortality rate and the length of stay at the ICU (Table II).

\section{Discussion}

A systemic inflammatory response is common in critically ill patients (19). When it is excessive or out of control, 
Table II. Effect of CBP treatment on clinical indicators

\begin{tabular}{lcccc}
\hline & & \multicolumn{3}{c}{ Clinical Indicators } \\
\cline { 3 - 5 } Group & $\mathrm{n}$ & $\begin{array}{c}\text { MODS } \\
\mathrm{n}(\%)\end{array}$ & $\begin{array}{c}\text { Mortality } \\
\mathrm{n}(\%)\end{array}$ & $\begin{array}{c}\text { Length of ICU } \\
\text { stay (days) }\end{array}$ \\
\hline A1 & 19 & $5(26.3)$ & $2(10.5)$ & $5.5 \pm 1.6$ \\
A2 & 19 & $6(31.5)$ & $2(10.5)$ & $4.5 \pm 1.4$ \\
B1 & 19 & $6(26.3)^{\mathrm{a}}$ & $2(10.5)^{\mathrm{a}}$ & $8.2 \pm 3.8^{\mathrm{a}}$ \\
B2 & 20 & $11(55.0)$ & $4(40.0)$ & $11.9 \pm 3.7$ \\
C1 & 19 & $9(47.4)^{\mathrm{a}}$ & $5(26.3)^{\mathrm{a}}$ & $11.5 \pm 4.2^{\mathrm{a}}$ \\
C2 & 19 & $14(73.7)$ & $10(52.6)$ & $14.0 \pm 3.8$
\end{tabular}

${ }^{\mathrm{a}} \mathrm{P}<0.05$ vs. B2 group. Groups: A, APACHE II score 15-19; B, APACHE II score 20-29; C, APACHE II score $\geq 30 ; 1$, CBP treatment; 2 , no CBP treatment. MODS, multiple organ dysfunction syndrome; ICU, intensive care unit; APACHE, Acute Physiology And Chronic Health Evaluation; CBP, continuous blood purification.

inflammation causes severe tissue damage (1). It has been reported that the plasma levels of IL- 6 and TNF- $\alpha$ are associated with the severity of the disease (20). Among cytokines and inflammatory mediators, TNF- $\alpha$ and IL- 6 have a key role in initiating the anti-inflammatory response (21). An elevation of IL- 6 and TNF- $\alpha$ stimulates the body to produce a large number of inflammatory factors, resulting in a cascade amplification of the inflammatory response (22). Therefore, dynamic monitoring of TNF- $\alpha$ and IL- 6 levels is of significance for the detection of the occurrence and progression of MODS (23-25). Furthermore, the prevention and treatment of any exacerbation of SIRS is key in the treatment of critically ill patients, which may be performed by either inhibiting the release or lowering the levels of pro-inflammatory cytokines (26). Therefore, elimination of multiple pro-inflammatory cytokines simultaneously and non-selectively may have therapeutic potential in preventing the aggravation of MODS.

As one of the most important advances in critical care medicine in recent years, the clinical application of CBP has been extended to the treatment of various types of critical illness of non-renal origin, including sepsis, MODS, decompensated cirrhosis, drug poisoning, acute decompensated heart failure and severe acute pancreatitis $(27,28)$. CVVH, a widely used CBP method in the clinic, has the advantage of clearing small- and medium-sized solutes. In the case of large volume displacement, CVVH also removes large solute molecules (29).

In the present study, it was observed that the levels of plasma inflammatory cytokines (TNF- $\alpha$, IL-6 and IL-8), PCT and endotoxin were significantly lower in patients treated with $\mathrm{CBP}$ (B1 and $\mathrm{C} 1$ ) than in those without CBP treatment (B2 and $\mathrm{C} 2$ ). This result indicates that $\mathrm{CVVH}$ effectively eliminates these circulating inflammatory factors. Similarly, 2 weeks after treatment, the improvement in certain clinical indicators, including the mortality rate and the length of stay at the ICU, in patients of the CBP group were significantly superior to those in the group that did not receive CBP. Of note, it appeared that CBP only provided a significant clinical benefit for a group of patients with a certain range of APACHE II score. It was observed that in patients with an APACHE II score between 15 and 19, CBP did not significantly improve the severity scores, cytokine levels, mortality rate and length of stay at the ICU. However, for patients with an APACHE II score of 20-29 or $>30$, all of the clinical indicators were improved by CBP intervention, as indicated by reduced severity scores and cytokine levels, a decreased mortality rate and a shortened length of stay at the ICU. The APACHE II score represents the disease severity and it has been demonstrated that it is positively associated with the risk of mortality $(30,31)$. The results of the present study suggest that an APACHE II score of 20-29 may be regarded as a selection criterion for blood purification treatment in the early stage of critical illness. In order to reduce the mortality rate of critically ill patients, CBP treatment should be performed as soon as possible. Our data showed that patients with APPACHEII score $>30$ also benefit from the CBP treatment. From the perspective of health economics and which patient group benefit most, we believe that it is more appropriate to perform CBP treatment when the patient's APPACHE II score is $\geq 20$.

In summary, the present study performed a comprehensive analysis to assess which group of critically ill patients benefited the most from CBP treatment based on their APACHE II score. The severity scores (APACHE II, MODS and SIRS), the plasma levels of inflammatory proteins (endotoxin, PCT, TNF- $\alpha$, IL- 6 and IL-8) and clinical parameters (mortality rate and ICU length of stay) were measured, and it was observed that patients with an APACHE II score of 20-29 benefited the most from CBP treatment, which is consistent with previous observations that $\mathrm{CBP}$ inhibits the inflammatory cascade amplification reaction by an 'off-peak effect', prevents the occurrence of MODS and reduces the mortality rate $(32,33)$. The present results indicate that the APACHE II score may be used to guide the treatment of patients with critical illness.

\section{Acknowledgements}

Not applicable.

\section{Funding}

The current study was supported by grants from the Scientific Research Project of Medical Research Program of Hubei Province (grant no. WJ2015MB240), the Wuhan Clinical Medical Research Project of Hubei Province (grant no. WX15A09) and the Wuhan Clinical Medical Research Project of Hubei Province (grant no. WX16E24).

\section{Availability of data and materials}

All datasets used and/or analyzed during the current study are available from the corresponding author on reasonable request.

\section{Authors' contributions}

RXZ designed the study. WD and CLH performed the experiments. RXZ, WD and CLH analyzed the data and 
prepared the manuscript. All authors read and approved the final manuscript.

\section{Ethics approval and consent to participate}

The current study was approved by the Ethics Committee of The First Hospital of Wuhan (Wuhan, China). Written informed consent was obtained from all patients or their next of kin.

\section{Patient consent for publication}

Not applicable.

\section{Competing interests}

The authors declare thst they have no competing interests.

\section{References}

1. Gong H, Sheng X, Xue J and Zhu D: Expression and role of TNIP2 in multiple organ dysfunction syndrome following severe trauma. Mol Med Rep 19: 2906-2912, 2019.

2. Jastrow KM III, Gonzalez EA, McGuire MF, Suliburk JW, Kozar RA, Iyengar S, Motschall DA, McKinley BA, Moore FA and Mercer DW: Early cytokine production risk stratifies trauma patients for multiple organ failure. J Am Coll Surg 209: 320-331, 2009.

3. Saadia R and Schein M: Multiple organ failure. How valid is the 'two hit' model? J Accid Emerg Med 16: 163-167, 1999.

4. Yao YM, Redl H, Bahrami S and Schlag G: The inflammatory basis of trauma/shock-associated multiple organ failure. Inflamm Res 47: 201-210, 1998

5. St John RC and Dorinsky PM: Immunologic therapy for ARDS, septic shock, and multiple-organ failure. Chest 103: 932-943, 1993.

6. Hanafusa N: Application of continuous replacement therapy: What should we consider based on existing evidence? Blood Purif 40: 312-319, 2015.

7. Intensive Care Society: Standards and recommendations for the provision of renal replacement therapy on intensive care units in the United Kingdom. Intensive Care Society, 2009.

8. Lee S, Hwang H, Yamal JM, Goodman JC, Aisiku IP, Gopinath S and Robertson CS: IMPACT probability of poor outcome and plasma cytokine concentrations are associated with multiple organ dysfunction syndrome following traumatic brain injury. J Neurosurg: Jan 11, 2019 (Epub ahead of print).

9. Finkel KW and Podoll AS: Complications of continuous renal replacement therapy. Semin Dial 22: 155-159, 2009.

10. Cheng J, Hu S, Lu H, Lei Q, Liu J, Yuan F and Chen R: Comparison of the therapeutic effectiveness of sustained low-efficiency dialysis (SLED) with continuous blood purification (CBP) in critically ill patients. Cell Biochem Biophys 67: 923-927, 2013.

11. Dehghani A, Abdeyazdan G and Davaridolatabadi E: An overview of the predictor standard tools for patient weaning from mechanical ventilation. Electron Physician 8: 1955-1963, 2016.

12. Sadaka F, EthmaneAbouElMaali C, Cytron MA, Fowler K, Javaux VM and O'Brien J: Predicting mortality of patients with sepsis: A comparison of APACHE II and APACHE III scoring systems. J Clin Med Res 9: 907-910, 2017.

13. Baue E: MOF, MODS, and SIRS: What is in a name or an acronym? Shock 26: 438-449, 2006.

14. Marshall JC, Cook DJ, Christou NV, Bernard GR, Sprung CL and Sibbald WJ: Multiple organ dysfunction score: A reliable descriptor of a complex clinical outcome. Crit Care Med 23: 1638-1652, 1995

15. Baek JH, Kim MS, Lee JC and Lee JH: Systemic inflammation response syndrome score predicts the mortality in multiple trauma patients. Korean J Thorac Cardiovasc Surg 47: 523-528, 2014.
16. NeSmith EG, Weinrich SP, Andrews JO, Medeiros RS, Hawkins ML and Weinrich M: Systemic inflammatory response syndrome score and race as predictors of length of stay in the intensive care unit. Am J Crit Care 18: 339-346, 2009.

17. Knaus WA, Draper EA, Wagner DP and Zimmerman JE: APACHE II: A severity of disease classification system. Crit Care Med 13: 818-829, 1985.

18. Jacobs S, Zuleika M and Mphansa T: The multiple organ dysfunction score as a descriptor of patient outcome in septic shock compared with two other scoring systems. Crit Care Med 27: 741-744, 1999.

19. Zhou Z, Guo F and Huan J: Fournier's gangrene with septic shock and multiple organ dysfunction syndrome. Int J Low Extrem Wounds 18: 94-96, 2019.

20. Zeng J: Values of detection of NF- $\mathrm{BB}$ activation level combined with IL-6 and TNF- $\alpha$ levels in peripheral neutrophils in the prediction of multiple organ dysfunction syndrome in patients with severe multiple trauma. Exp Ther Med 16: 2478-2482, 2018.

21. Wang F, Guan X, Yang J, He W, Wei Y, Chen H and Li Y: Differential expression and significance of endoplasmic reticulum golgi intermediate compartment 1 in precancerous gastric lesions and gastric cancer. Am J Med Sci 355: 228-234, 2018

22. Li A, Xiong J and Chen Z: IL-6, TNF- $\alpha$, and iNOS is associated with decreased colonic contraction in rats with multiple organ dysfunction syndrome. J Surg Res 178: e51-e57, 2012.

23. Lee JH, Kim HY, Bae EH, Kim SW and Ma SK: Biomarkers predicting survival of sepsis patients treated with continuous renal replacement therapy. Chonnam Med J 53: 64-68, 2017.

24. Shimazui T, Matsumura Y, Nakada TA and Oda S: Serum levels of interleukin-6 may predict organ dysfunction earlier than SOFA score. Acute Med Surg 4: 255-261, 2017.

25. Seymour CW, Liu VX, Iwashyna TJ, Brunkhorst FM, Rea TD, Scherag A, Rubenfeld G, Kahn JM, Shankar-Hari M, Singer M, et al: Assessment of clinical criteria for sepsis: For the third international consensus definitions for sepsis and septic shock (Sepsis-3). JAMA 315: 762-774, 2016.

26. Lee YJ, Park CH, Yun JW and Lee YS: Predictive comparisons of procalcitonin (PCT) level, arterial ketone body ratio (AKBR), APACHE III score and multiple organ dysfunction score (MODS) in systemic inflammatory response syndrome (SIRS). Yonsei Med J 45: 29-37, 2004.

27. Ávalos-López M, Pérez-López MJ, Aguilar-Martínez C, Díaz-Franco AMC, Esquivel-Chávez A and Baltazar-Torres JA: Prediction of acute kidney injury in critically ill patients treated with intermittent hemodialysis versus CRRT. Rev Med Inst Mex Seguro Soc 55: 696-703, 2017 (In Spanish).

28. Yoon J, Kim Y, Kym D, Hur J, Yim H, Cho YS and Chun W: Subgroup analysis of continuous renal replacement therapy in severely burned patients. PLoS One 12: e0189057, 2017.

29. Li YN, Zhou LX, Qiang XH, Yu TO, Mao KJ, Feng B, Wen WB, Zou YC, Li WY and Li C: Effect of continuous blood purification and thymosin alpha1 on the cellular immunity in patients with severe sepsis: A prospective, randomized, controlled clinical trial. Zhongguo Wei Zhong Bing Ji Jiu Yi Xue 21: 139-142, 2009.

30. Zhou R, Weng F, Dai W and Yan J: The organ protective effects and timing of continuous blood purification in the treatment of severe sepsis: A double-blind randomized controlled trial. Zhonghua Wei Zhong Bing Ji Jiu Yi Xue 28: 241-245, 2006 (In Chinese).

31. Sabatino A, Theilla M, Hellerman M, Singer P, Maggiore U, Barbagallo M, Regolisti G and Fiaccadori E: Energy and protein in critically ill patients with AKI: A prospective, multicenter observational study using indirect calorimetry and protein catabolic rate. Nutrients 9: pii: E802, 2017.

32. Allegretti AS, Steele DJ, David-Kasdan JA, Bajwa E, Niles JL and Bhan I: Continuous renal replacement therapy outcomes in acute kidney injury and end-stage renal disease: A cohort study. Crit Care 17: R109, 2013.

33. Quinto BM, Iizuka IJ, Monte JC, Santos BF, Pereira V, Durão MS Dalboni MA, Cendoroglo M, Santos OF and Batista MC: TNF- $\alpha$ depuration is a predictor of mortality in critically ill patients under continuous veno-venous hemodiafiltration treatment. Cytokine 71: 255-260, 2015. 